Please do not remove this page

RMIT

UNIVERSITY

\title{
Institutional tipping points in organizational climate change adaptation processes
}

Fuenfgeld, Hartmut

https://researchrepository.rmit.edu.au/esploro/outputs/9921860547501341/filesAndLinks?institution=61RMIT_INST\&index=null

Fuenfgeld, H. (2017). Institutional tipping points in organizational climate change adaptation processes. Journal of Extreme Events, 4(1), 1-29. https://doi.org/10.1142/S2345737617500026 Document Version: Accepted Manuscript

Published Version: https://doi.org/10.1142/S2345737617500026

Repository homepage: https://researchrepository.rmit.edu.au

(C) World Scientific Publishing Company

Downloaded On 2023/04/26 10:56:53 +1000 
Thank you for downloading this document from the RMIT Research Repository.

The RMIT Research Repository is an open access database showcasing the research outputs of RMIT University researchers.

RMIT Research Repository: http://researchbank.rmit.edu.au/

\section{Citation:}

Fuenfgeld, H 2017, 'Institutional tipping points in organizational climate change adaptation processes', Journal of Extreme Events, vol. 4, no. 1, 175002-1, pp. 1-29.

See this record in the RMIT Research Repository at:

https://researchbank.rmit.edu.au/view/rmit:43786

Version: Accepted Manuscript

\section{Copyright Statement:}

(c) World Scientific Publishing Company

Link to Published Version:

https://dx.doi.org/10.1142/S2345737617500026 


\title{
Institutional tipping points in climate change adaptation processes
}

\author{
Hartmut Fünfgeld ${ }^{1}$ \\ ${ }^{1}$ Centre for Urban Research, School of Global, Urban and Social Studies, RMIT \\ University, Melbourne (Australia)
}

\begin{abstract}
In human systems, effective climate change adaptation will involve institutional change, to facilitate localized and context-sensitive adaptation and social transformation. As the need to adapt to climate change becomes increasingly recognized across public and private sector organizations, an improved understanding of how adaptation occurs and what supports and what hinders adaptation in a given organizational context will be critical.
\end{abstract}

From the perspective of sociological institutionalism, institutions are created and altered in interaction with their normative and cultural environment. In a social context where considering climate change impacts is a new agenda, processes of institutional change can be identified, tracked and interpreted by using the concept of institutional tipping points. Borrowing from environmental sciences and climatology, institutional tipping points are situations where small changes in dominant norms, values and rules within a social system lead to lasting institutional change in that system. Key features of institutional tipping are the gradual emergence of an alternative attractor regime, which can usually be linked to broader changes in the institutional environment, and the activity of a small group of actors who push the boundaries of current dominant institutions. An institutional interpretation of tipping points opens up opportunity for interpreting institutional change retrospectively, while also providing insights into how 'virtuous' tipping points in social systems can be engendered through policy intervention and social mobilization. 


\section{Introduction}

Efforts to adapt to a changing climate are a critical part of the human response to anthropogenic climate change, in particular if people, ecosystems and assets most vulnerable to temperature increases are to be protected from harm or degeneration. To date, it seems that those sectors with significant exposure and/or sensitivity to climate change are at the forefront of adaptation. As climate change becomes an increasing reality and pervades ever more human systems, planned climate change adaptation will be required across sectors and scales (Adger et al. 2005; Arnell et al. 2014). Not only those with direct exposure to climate change impacts will need to interact with the socio-economic and institutional dimensions of adaptation, but also individuals, community groups, private businesses and public sector organizations with to date limited concern about sea-level rise, more intense heatwaves and more severe flooding.

Organizations working in sectors such as health care, agriculture and urban planning are increasingly aware of the current and projected impacts of climate change, but for adaptation to be effective, these will need to move from being 'climate literate' to being able to assess the risks of climate change to their services and operations, their customers and clients. In many cases, they will need to fundamentally change their way of doing things, by switching all or parts of their efforts from incremental adaptation to transformation (Pelling 2011; Park et al. 2012). Understanding what enables organizations (broadly defined here as coherently configured collectives of people working towards a shared purpose) to make progress with adaptation becomes an important issue, and one where interdisciplinary social science research has taken significant interest and can make a major contribution (see Berkhout et al. 2006; Pelling et al. 2008; Berkhout 2012; Linnenluecke et al. 2013). In this setting, the purpose of this paper is to contribute conceptually material to the rapidly growing discourse about institutional drivers and barriers to adaptation (Measham et al. 2011; Lawrence et al. 2013; Walker et al. 2014; Leck \& Roberts 2015). In the following, I draw on theories of sociological institutionalism (Meyer \& Rowan 1977; Powell \& DiMaggio 1991) to conceptualize not 
only individual institutional drivers for change but their collective effect on organizational change and transformation. I do so by borrowing the concept of tipping points from ecology, attempting to transpose it into the social realm, and relating it to the specific institutional needs of transformative adaptation to climate change. I hope that this largely conceptual contribution can elicit new information about organizational adaptive capacity and the potential for transformation in a variety of institutional contexts and, ultimately, help decision-makers and practitioners develop a vision for transformative adaptation for their own organizations. The logic is that if we better understand the factors that contribute to and impede transformative action on climate change adaptation, we are better able to support social, political and economic processes that foster adaptation and develop transformative solutions.

\section{Institutional dimensions of climate change adaptation}

Human adaptation to climate change is an emerging agenda for policy and practice, which was borne out of a growing understanding that anthropogenic climate change was well underway and that a planned response was necessary if harm to humans and non-humans was to be averted or minimized (see IPCC 2014). Essentially, adaptation to climate change requires change. Existing ways of doing things need to be altered in light of current or projected climate change impacts, to reduce immediate or future environmental and socio-economic arising from climate change impacts such as rising sea levels, more frequent and more intense extreme weather events, or drying trends and drought.

This problem structure has defined the broad aim of any solutions to be devised, yet in between the problem and solution framing (Bardwell 1991) lies an institutional space, where old institutions cease to exist and new ones appear or are purposefully created as ideas about adaptation are translated into feasible adaptation actions. Institutions, defined by North (1991) as 'the rules of the game', facilitate and constrain human interaction in either formal or informal ways. They consist of 
formal rules, regulations and procedural steps on the one hand and informal agreements, social and cultural norms of behavior, all of which govern the functioning of a society.

Assuming that adaptation equals social change, it will require that existing institutions are altered and new ones are formed. These emergent 'adaptation institutions' do not occupy empty space within an institutional vacuum. Rather, their genesis is inextricably enmeshed with an existing network of formal and informal institutions that themselves are constantly in flux (Garschagen 2011). This process of enmeshing is particularly evident in adaptation, where it is conceivable that there is almost no part of human society that will not be affected by the impacts of climate change in one way or another. Any process of institutionalizing adaptation is therefore both highly dynamic and highly contextual, where an array of existing institutions is altered, new ones are added in, and some old ones cease to exist or are deliberately eliminated. This process entails covert and overt forms of negotiation and judgment, and hence adaptation is necessarily political and mediated by normative ideas about specific adaptation goals, processes and responsibilities.

\subsection{Extreme events as catalysts for change}

Yet what do we know about the institutional processes that shape adaptation? In areas of high exposure, the occurrence of extreme weather events, for example, can suspend otherwise pervasive institutional inertia (Munck af Rosenschöld et al. 2014) during short-lived 'windows of opportunity', as politicians are keen to demonstrate their ability to exercise control and respond quickly, while moral and humanitarian imperatives make it relatively easy to garner the financial resources required for decisive and immediate (re-)action, from governments and individuals compelled to help. Extreme events and natural disasters also raise awareness and provide opportunities to inform people about the risks involved. Nowhere was this more evident as with the Indian Ocean tsunami in 2004, which, triggered by extensive media coverage of the vast and confronting impact of the disaster, created an almost global literacy of the physical causes and consequences of submarine earthquakes - as well as an outpour of private donations from around the world. As a result, early 
warning systems were developed, improved and rolled out in most countries around the Indian Ocean, the Pacific and in other parts of the world, and the term tsunami became standard vocabulary of school children in places geographically far removed from tsunami threats.

In the realm of climate change, large climate-induced disasters, such as the European heatwave of 2003, Hurricane Katrina in the United States in 2005, and the 2009 Black Saturday bushfires in Victoria, Australia, were events that not only gripped the attention of local citizens, politicians and global media audiences alike, they also catalyzed action, leading to institutional change with consequences that often reached far beyond the administrative boundaries of the initial event.

There is no guarantee that the political opportunity that arises post-event is seized to transform the system in question, and often, action turns out to be reactive, knee-jerk and mainly concerned with reinstating or making minor improvements to the status quo pre-event.

\subsection{Institutional tipping points in human systems}

In many instances, the pervasiveness of climate change impacts will make it difficult to empirically establish and verify a causal link between an event occurring and a subsequently detected change in institutions. Yet whether driven by the occurrence of extreme weather events or not, understanding how institutional change and transformation occur is important for being able to advance adaptation in human systems. Here, the concept of institutional tipping points can help conceptualize institutional change at a social group level, and provide a framework for collecting empirical evidence of such change occurring.

In scholarly work, the tipping point concept has been borrowed from the natural sciences, where it has been influential in disciplines such as ecosystem science (Scheffer et al. 2001; Scheffer 2010), climatology (Alley et al. 2003; Levermann et al. 2011) and geomorphology (Kirkby 1995; Phillips 2006). In its use across disciplines, a main feature of the concept is that tipping points result in changes that may be irreversible. This means that their potential impacts are significant (whether 
positive or negative), resulting, for example, in permanent damage to communities, landscapes or ecosystems.

In climate science, for example, tipping points have been commonly defined as 'critical threshold[s] at which a tiny perturbation can qualitatively alter the state or development of a system', e.g. the global climate system (Lenton et al. 2008). The tipping point concept of has been popularized not least since Malcolm Gladwell's (2000) bestselling book with the same title and is often used in its broad sense, to point out that little changes to a system can make a big difference to its future state and further development. According to Lenton (2013), the notion of tipping points was first used as a sociological term by Grodzins (1957), who discussed racial segregation in the United States, where 'tip points' identified situations where white populations were starting to 'flee' neighborhoods following the arrival of non-white residents. This early application of social tipping points showed that seemingly small ideas and trends, through a process of changing established values systems, can eventually result in a social movement that might 'revolutionize' a social system or a subset thereof.

\subsection{Applying tipping points to institutional change}

However, transposing the tipping point concept into the social realm comes with a number of epistemic and methodological challenges. Social and institutional change is notoriously difficult to predict - especially in subsystems where critical social processes are hard, if not impossible, to quantify and where most prediction about social trends, therefore, involves elements of crystal ball gazing. Contrary to climatology, where early warning indicators are used to diagnose the vulnerability of systems and to forecasting the time of tipping well ahead of noticeable changes to such system elements (e.g. of the Atlantic Meridional Overturning Circulation (AMOC); Schellnhuber 2009), the complexity of human systems and the political processes that govern them makes is virtually impossible to use tipping points as a predictive or projective concept. Yet this does preclude employing the concept of tipping points in constructive, interpretive ways in the social sciences. 
The notion of an institutional tipping point can be conceived as a useful diagnostic device that can help understand retrospectively what constellations of people, events and processes triggered lasting change to institutions - irrespective of normative questions as to whether such change was deliberate or not. From a policy and decision science point of view, such knowledge on the characteristics of institutional tipping points can then help inform processes where social change is indeed wanted and intended. In the social realm, it is not only of interest which factors led to reaching a tipping point but also cases where such tipping points seemed possible but did not eventuate, either because emerging trends were deliberately and forcefully stopped or because they were overtaken by other developments.

Naturally, observing small instances of institutional change empirically, supported by valid evidence, is challenging in the first place - and it is likely to be all the more challenging the larger the unit of analysis. Small organizations, such as households or families, therefore, appear to be a more appropriate scale for gathering empirical evidence of institutional tipping points than larger institutional domains, such as nations or international regimes.

\subsection{Towards a framework for detecting and encouraging virtuous institutional tipping points}

Despite its underlying negative connotations, the concept of tipping points can equally be applied to significant changes that result in normative improvements to a situation, as well as to the more frequently discussed deterioration of systems and their components. Lenton, in his comprehensive theoretical discussion on environmental tipping points, identifies the need to encourage "„virtuous" tipping points in human systems' (Lenton 2013: 20), through changing world views, collective decision-making and sociotechnical transitions. The main interest of this article lies in conceptualizing such virtuous tipping points and their transformative potential. Drawing on Lenton's work, there is scope to outline a multi-scale conceptual framework for examining virtuous tipping points (Figure 1), which is discussed in the following. 
The proposed framework draws on core assumptions of sociological institutionalism (Meyer \& Rowan 1977; Powell \& DiMaggio 1991; Hall \& Taylor 1996), namely that the notion of institutions includes not only formal and informal rules and norms, but also the entirety of symbolic and cultural systems that enable or hinder human interaction.

Figure 1: Emergence of virtuous institutional tipping points across scales

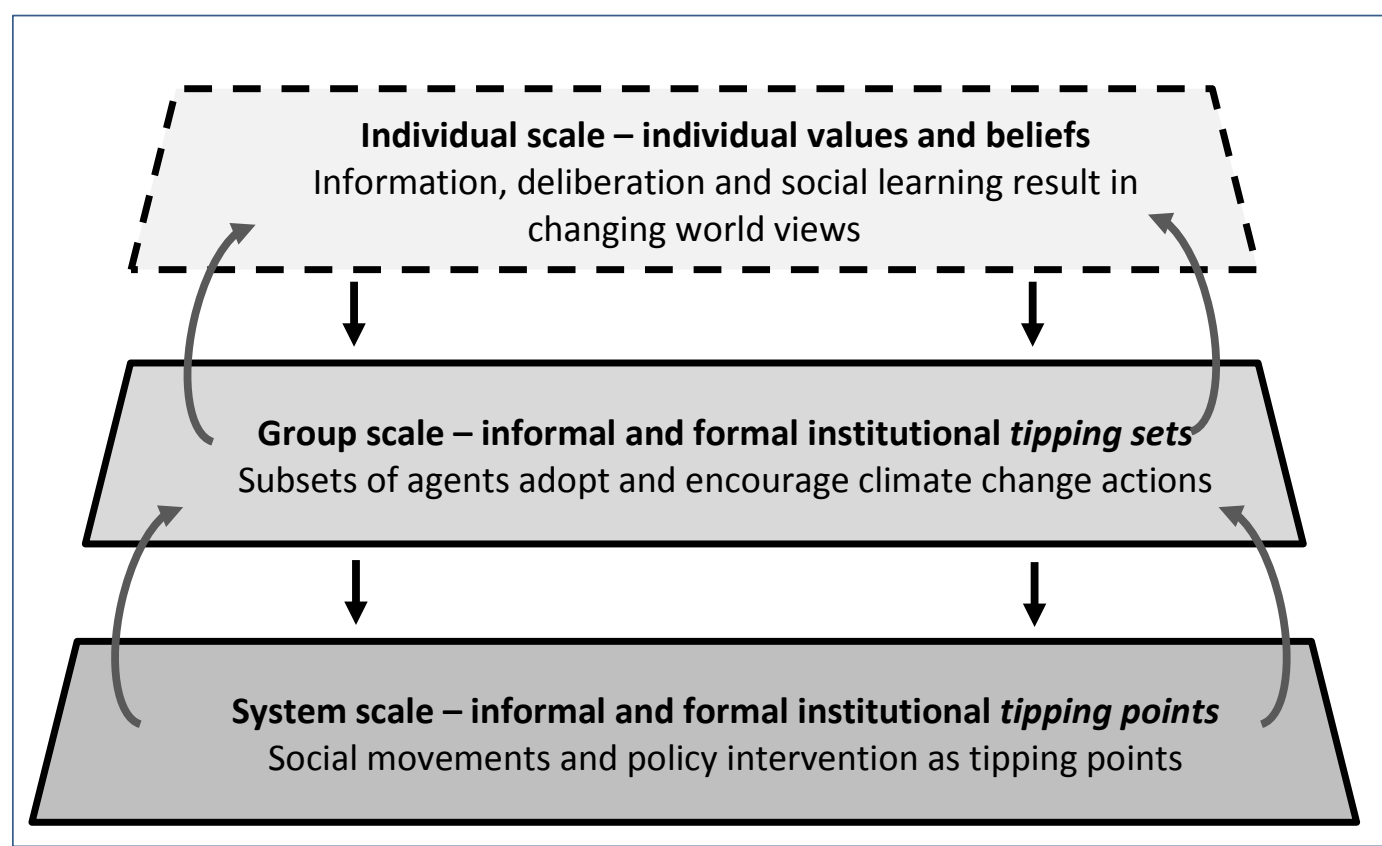

Source: Author's draft, based on Lenton 2013.

\subsubsection{Individually held values and beliefs as a starting point}

The individual scale is relevant as the origin for all institutional change, recognizing that individually held values and beliefs can be both an obstacle to, and a catalyst for, the development of new informal institutions. Much of the theoretical ground for the interplay of individually held beliefs and support for action on anthropogenic climate change has been covered by research in cognitive psychology (Gifford 2011; Gifford et al. 2011), political science (Wiest et al. 2015), the philosophy of science (Thargard \& Findlay 2010), and in communication studies (O'Neill \& Nicholson-Cole 2009). It 
is beyond the scope of this paper to discuss endogenous individual value formation and its associated cognitive and psychological processes.

From the perspective of institutional change, the starting point is a theoretical situation where existing institutions are fully and well aligned with a dominant value-based regime, which, following the terminology used by Lenton (2013) can be called 'attractor regime' (Figure 2-A). The attractor

Figure 2-A: Institutions fully aligned with dominant attractor regime

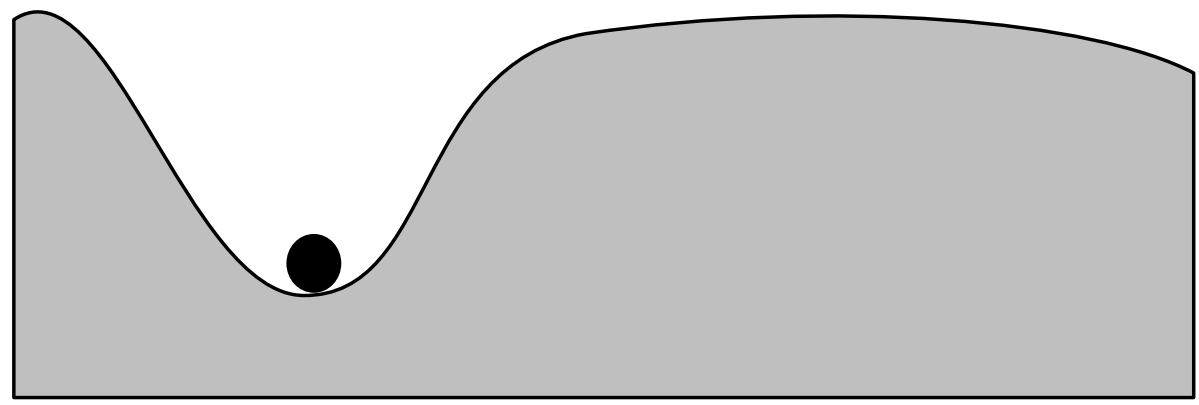

Formal and informal institutions enable a single, dominant attractor regime. In the absence of alternative regimes, there is little reason or incentive to change institutions.

Source: Author's draft, based on Lenton 2013.

regime can be broadly described in societal meta-narratives, such as 'democracy is an important public good' or 'climate change isn't real', which are grounded in culturally defined norms and belief systems. In our theoretical starting situation, the attractor regime is dominant and powerful and there is little incentive, nor opportunity, for institutions to change.

When different actors' opinions change in favor of climate change action, they begin to reject the null hypothesis for 'anthropogenic climate change is real and requires action'. They are likely to do so not in isolation but through observation, discourse and deliberation with their peers, at home, at the work place or in other types of place-based or virtual communities. At this point, an alternative attractor emerges, along with a potential institutional tipping point, as increasing social interaction takes on the form of social learning among members of a group. Here, non-formalized processes of learning take place between individuals, through discursive practice, knowledge exchange, and experimenting, which often also involves engaging with innovators and experts external to the 
group. These interactions result in gradual minor adjustments, e.g. establishing new informal institutions, grounded in the fact that individual world views are being renegotiated and, as a consequence of such renegotiation processes, changed towards the acceptance of an altered set of values and beliefs. Informal institutions may include, for example, actively seeking new information on climate change and sharing this with colleagues; discussing the need to adjust programs and policies to consider climate change impacts and risks; or simply allowing for and encouraging informal debates about climate change phenomena in a tea break (which people would have shunned prior to their value system changing). However, these nascent changes are not supported by the broader cultural environment, which is why the current attractor regime maintains its dominance and small pushes towards informal institutional change are rapidly corrected (e.g. by the breakdown of newly formed social learning networks, because new initiatives prove unpopular, or because of a lack of resourcing; Figure 2-B).

Figure 2-B: Gradual emergence of an alternative attractor and potential tipping point

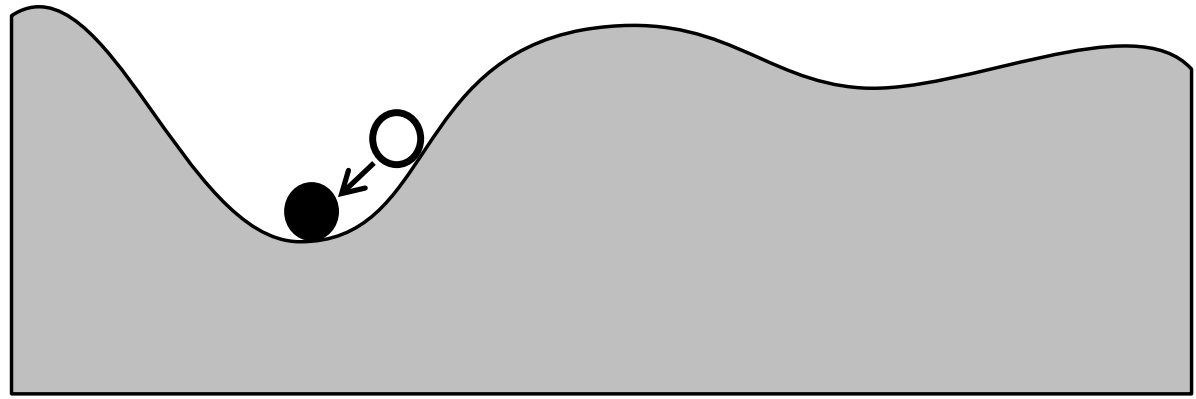

Through factors such as observed events and new scientific knowledge, an alternative attractor emerges, while the dominant attractor begins to weaken. Mild pushes to adjust informal institutions are rapidly corrected, in line with the the dominant institutional regime. Source: Author's draft, based on Lenton 2013.

Initially, such correction may occur despite the alternative attractor becoming consolidated, e.g. as new scientific evidence supporting an alternative value set becomes available. Gradually, new institutional patterns emerge that are pushing for change but, despite no longer being corrected immediately because of a weakening attractor, there is still a strong adherence to the currently 
dominant regime. Such adherence may be caused by a resistance to change in the broader cultural environment (e.g. the electorate) or due to path dependency (e.g. in the form of budgets needing to demonstrate alignment with a five year strategic plan). This behavior is akin to what has been

Figure 2-C: Consolidation of alternative attractor and lowering of tipping

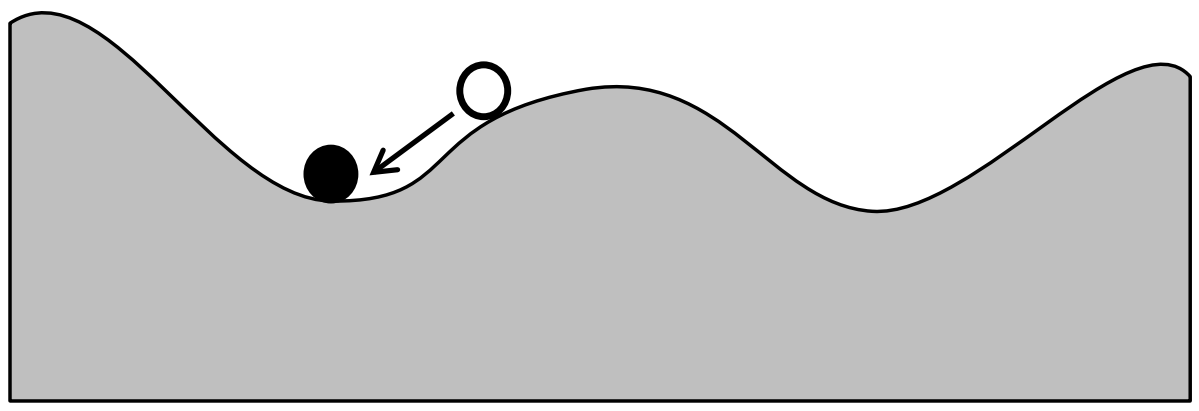

As the alternative attractor consolidates, e.g. due to mounting evidence for its validity, informal institutions push towards the tipping point but are not enduring.

Source: Author's draft, based on Lenton 2013.

termed institutional inertia (Munck af Rosenschöld et al. 2014).

\subsubsection{Emerging tipping sets at the group scale}

If this process of social learning progresses and is not stifled by contravening events or willful interference, more and more individuals become involved, and social groups may start to formalize their newly found convictions: a group of actors might adopt a tipping set ${ }^{1}$ of informal institutions that become increasingly formalized (Figure 2-D). For example, sporadic and ad-hoc information seeking is replaced by signing up to news feeds and publication updates issued by leading research institutes; funding might be sought to systematically assess an organization's climate change risks; and informal chats in the tea room may evolve into inviting an expert on climate change adaptation to give a lunch time talk on climate change impacts.

\footnotetext{
${ }^{1}$ Lenton (2013: 21) actually applied the term tipping set to groups of agents, such as nations, rather than the actions or rules that govern their interaction. However, for conceptualising institutional tipping points I have opted for considering sets of formal and informal institutions rather than social entities as constitutive of tipping sets, to stay consistent within the logic of collective agency among social groups.
} 
Over time, such processes of expanding and formalizing institutions can generate an organization's culture (or that of an otherwise defined community) as a critical mass of individuals forms, who become known for their convictions and actions and who inspire or co-opt others to become involved. Gradually, more people follow suit and adjust their own, long-held beliefs. Here, a positive institutional feedback loop becomes apparent, where the acceptance of the need for climate change action has become the new social norm, which becomes increasingly difficult to resist or ignore.

Figure 2-D: Tipping sets pull some social groups towards alternative

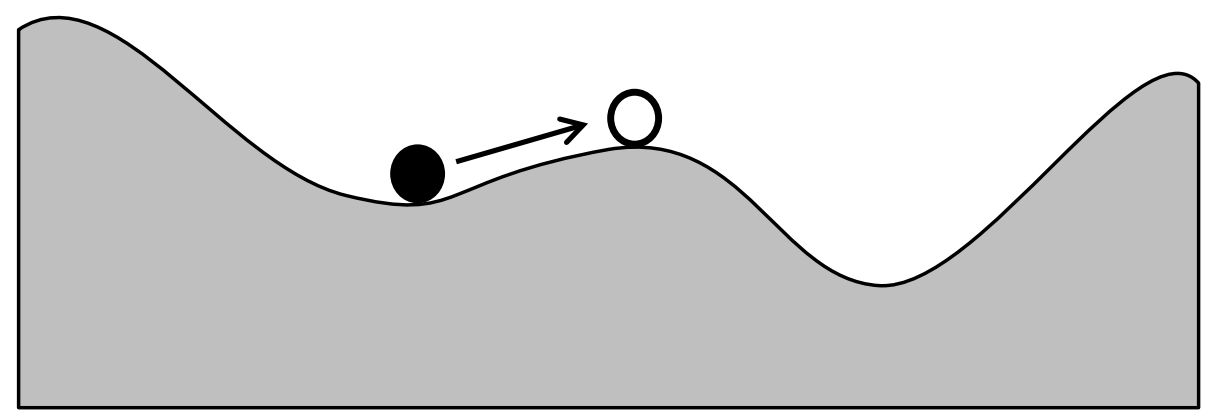

As evidence and support for the alternative attractor increases and the trigger point lowers, sub-groups develop sets of informal and increasingly formalised institutions (tipping sets) that precede a broader move towards a tipping point. Source: Author's draft, based on Lenton 2013.

These significant changes then result in increasing popular support for action and its associated informal institutions - for example that, depending on the social group, it is no longer socially acceptable to publicly discredit climate science - which in turn adds to the political pressure to design and implement formal institutions in support of the emerging political agenda. The emergence of such closed-loop, self-amplifying positive feedback is both necessary factor for and characteristic symptom of a system tipping into a different state (Lenton 2013). It marks a runaway situation where the groups have pushed past a critical institutional tipping set and established a new 'attractor regime' (ibid.) that, though not necessarily irreversible, has gained sufficient momentum and support to allow for further institutionalization, e.g. by lobbying governments and regulating/standard-setting agencies, such as peak sector bodies, to develop their respective 
positions on the issue of climate change action. New formal institutions, such as feed-in tariffs designed to support a move to a different energy regime, emerge in the form of strategic or regulatory policy or new sector-wide standards that are designed to encourage moving whole sectors, professions, or place-based communities towards the new attractor.

\subsubsection{Systemic tipping driven by broad social and political acceptance}

Eventually, the acceptance of the need for climate change action passes a tipping point and becomes a formalized consideration in planning and decision-making by all key actors involved. At this stage, institutional functions have been realigned with accepted dominant beliefs, which are represented by the altered attractor regime. The situation is characterized by a lowering tipping point threshold, where it becomes increasingly difficult to adhere to the old attractor regime (Figure 2-E). In colloquial terms, the social pressure is too great to be able to resist the new organizational culture.

Figure 2-E: Formalised institutions facilitate shift towards new attractor regime

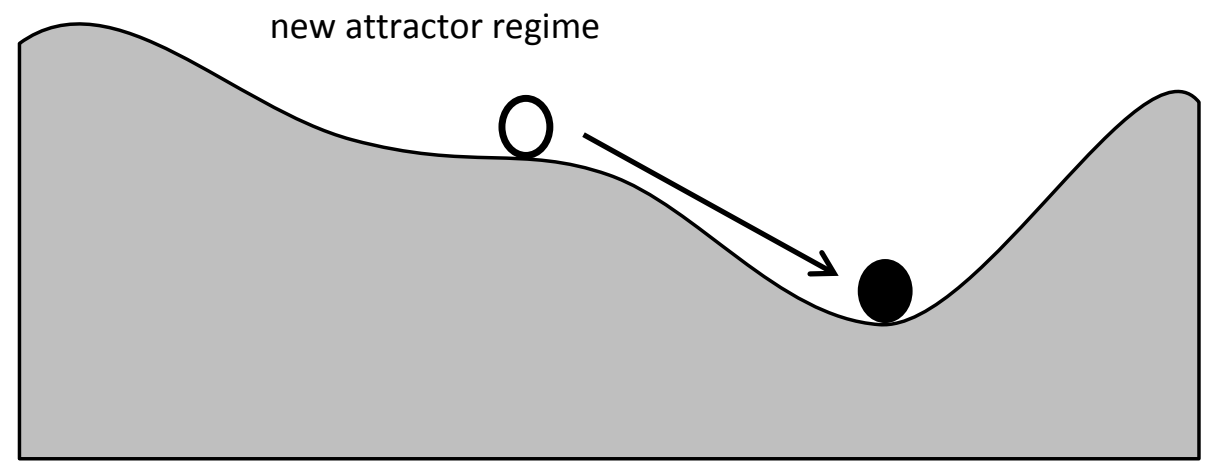

Formal institutions are created that establish the alternative attractor as new dominant institutional regime, with relatively stable institutions. Regulations have increased the attractor's power, while social processes and other formal/informal institutions have lowered the tipping threshold, making it harder for alternative institutions to prevail in this new regime.

Source: Author's draft, based on Lenton 2013.

At the international scale, for example, the Paris agreement on climate change marks a likely institutional tipping point, where nations who have been reluctant to commit to climate change mitigation and adaptation, have agreed to a binding agreement to act in concert with the global community. The recently ratified agreement is likely to spark at least some transformative action at 
the scales of national and subnational government, in the private sector, and in international development cooperation and will make it more difficult for political and business leaders to adhere to a culture of climate change skepticism.

\section{Evidence of institutional tipping points in public sector organizations}

The concept of institutional tipping points outlined above can be applied to social systems of different size and scale, where it can be used to examine existing attractor regimes, identify emerging tipping points, and analyze processes and events that constitute tipping sets of social groups or actual tipping points. Epistemic and in particular methodological constraints are likely to limit any empirical social research into institutional tipping points to social groups of a size that can readily be characterized and described. The following two examples illustrate such an application for the organizational and sectoral scale, drawing on qualitative data collected as part of social research projects that investigated the capacity of organizations to plan and implement climate change adaptation measures in Australia.

\subsection{Methodology}

The data used in the following account was collected as part of two research projects, funded by the Victorian Government (Australia) through the Victorian Centre for Climate Change Adaptation Research (VCCCAR). Project one, implemented from 2010 to 2012, was called 'Framing multi-sector and multi-level adaptation in the Victorian context' and explored how local governments in the state of Victoria were coming to terms with climate change adaptation as an emerging policy agenda, how adaptation was interpreted and implemented across the organization, and what approaches were used. As part of the project, a peer-reviewed summary of the then state of the art of knowledge on climate change adaptation concepts and approaches (Fünfgeld \& McEvoy 2011)as they related to public sector organizations was conducted, followed by case study research in three local 
governments: the City of Greater Bendigo, the City of Greater Geelong, and the City of Melbourne. Case studies involved a review of recent documents relevant to climate change adaptation and conducting a series of four to seven focus groups (60min duration) in each organization, in which up to eight staff from across the respective organization participated. In Bendigo, six semi-structured interviews with senior local government managers were also carried out, as well as regular informal discussions with the City's Sustainable Environment Unit. Focus groups and semi-structured interviews were transcribed and analyzed using text-based queries in NVivo10 and 11.

The second project, called 'Implementing adaptation tools to enhance adaptive capacity in the community and natural resource management sectors', was conducted from 2012 to 2014 . The project used a transdisciplinary approach to assess current impacts of climate change on two key sectors (community services and natural resource management) in the state of Victoria, as well as the sectors' perceived capacity to adapt to climate change. Apart from an extensive review of the literature, a total of 72 semi-structured interviews were conducted across the two sectors. A significant part of the project involved participatory action research, where selected organizations from the community services sector tested a range of adaptation decision-support tools to advance their organization's adaptation planning and implementation. Interview transcripts, researcher notes and other documents were collated, coded using a purposefully designed analytical framework, and analyzed in NVivo10.

In the following, I discuss evidence of different attractor regimes, tipping sets and tipping points across the three sectors covered in the two projects mentioned above. I distinguish between different scales, from the organizational scale in the first case study to the sectoral scale in the second example.

\subsection{Case study 1: Creating the conditions for supporting adaptation in local government}


The City of Greater Bendigo is a major regional center and the third largest urban area in Victoria, located in Central Victoria, about 150 kilometers north-west of Melbourne. Greater Bendigo has a population of just over 100,000 and covers almost 3,000 square kilometers of the central Victorian landscape, including several smaller towns and villages in the rural areas of the Loddon region. As a consequence of climate change, Central Victoria faces a hotter and drier future, with fewer rainy days but increasing rainfall intensity. This means that the number of hot days and days of extreme fire danger will increase. Lower rainwater runoff and reduced flows in the region's rivers and streams may reduce water availability and water quality.

It is fair to say that in Australia prior to 2006-07, the dominant attractor regime was one were climate change was widely regarded with skepticism among the general public. While many local governments had been active in climate change mitigation for years, e.g. by inventorying and reducing greenhouse gas emissions from buildings, fleets and street lighting, this action was often not met with widespread support from the public, particularly in rural areas with more conservative electorates. Equally, until 2006 at least, climate change adaptation was not on the agenda of local governments in Australia (with the exception of a small number of local governments in metropolitan areas). A guidebook on climate change risk management for government and business, published by the Australian Government in 2006, along with the release of the Intergovernmental Panel on Climate Change's Fourth Assessment Report in 2007, and Federal government funding supporting local governments in undertaking climate change risk assessments gradually provided an alternative attractor regime at the national and international scale. However, within a local government organization, such as the City of Greater Bendigo, the dominant attractor remained one where climate change adaptation did not have broad support. As data from the interviews and focus group discussions suggest, this was mainly due to three impeding factors: (1) the absence of a clear business case for adaptation, (2) a lack of support by senior executives and local politicians, and (3) lack of clarity about what approach to use for climate change adaptation, to ensure efficacy and efficiency of process. 
Since about 2006, the Sustainable Environment Unit had engaged in external capacity building activities on climate change adaptation, e.g. by sending unit staff to seminars and expert meetings on the topic, and by attending conferences and networking forums on adaptation, which were increasingly organized across the country. These activities, endorsed internally by the unit manager, were in many ways responding to developments in the institutional environment outside of the organization (commensurate with the emergence of an alternative attractor), including an emerging shift in policy towards adaptation at the national and state levels. Within the City of Greater Bendigo administration, however, such capacity building and networking activities were confined to the Sustainable Environment Unit (SUE), which formed an institutional tipping set as the alternative attractor deepened. However, other than increased formal and informal network participation, no formal process of institutionalizing climate change adaptation had occurred, and adaptation was largely seen as a single agenda of the SUE.

This changed in 2008, with the development and ratification of the new 2009-2013 Council Plan, the organization's key strategic planning document (City of Greater Bendigo 2009). Over the past few years, the SUE, led by an experienced local government manager, successfully advocated within the administration and to elected councilors that the municipality was facing significant climate change risks and that this was an imperative for action on adaptation planning. In the 2009-2013 Council Plan, climate change was mentioned for the first time as an 'important factor already affecting our population' (ibid: 11), and under the 'built and natural environment' theme of the plan, the following strategic objective was included: 'Be a leader and role model in climate change adaptation and ecologically sustainable development' (ibid: 15). This objective was translated into a concrete action for the year 2011-12, also mentioned in the Council Plan: 'Complete climate change adaptation action plan for City of Greater Bendigo' (ibid: 16).

The inclusion of climate change adaptation as a strategic organizational objective marks an organizational tipping point, where the organization as a whole adopted an alternative attractor 
regime where climate change adaptation was unquestioned and supported - an attractor that had gradually emerged in the broader policy environment since 2006.

The strategic plan, as a binding document that guides the administration's actions over a five year period, provided the basis for further institutionalization and embracing climate change adaptation formally and informally as a new policy agenda for the City of Greater Bendigo. Having adaptation included in the Council Plan meant that the strategic objective could be referenced in the budget bidding process and that internal funding would be made available for adaptation. Interestingly, the action mentioned in the Council Plan shows that it was possible to include adaptation as a strategic objective without having a clear-cut business case; rather, it was deemed that significant adaptation planning was necessary to enable the organization to develop its own approach and set of measures to adapt to climate change. Developing a context-specific business case for investing in adaptation was taken on as one of the first steps of the planning process.

This close alignment of adaptation with the organization's strategic planning enabled the SEU to frame climate change adaptation as a whole-of-organization approach, with the aim to eventually extend the responsibility for adaptation form the SEU to other parts of the organization. The institutional tipping point resulted in a broader move towards building staff capacity, e.g. by inviting expert adaptation scholars and practitioners to give lunch time seminars, and by seeking out partnerships with universities and becoming actively involved in adaptation research projects. Gaining the support of senior executives and having adaptation included in the Council Plan therefore also paved the way for addressing major other barriers to adaptation, including clarifying the business case and developing a customized approach to adaptation that was owned by staff across the organization.

\subsection{Case study 2: Strategic change among Primary Care Partnerships}

The state government of Victoria funds, through its Department of Health and Human Services (DHHS), so-called Primary Care Partnerships (PCPs) to maximize health and well-being outcomes, 
promote health equity, and avoid unnecessary hospital presentations and admissions (Victorian Government 2013). A total of 28 PCPs exist across the state, covering distinct geographic areas from metropolitan Melbourne to remote rural areas in western, northern and eastern parts of the state (Department of Health and Human Services 2015). PCPs are complex, multi-organizational partnerships of health and community organizations (Delaney 2009). The PCP typically consists of two to four staff members in total. The PCP consists of approximately ten to 20 member agencies, who sign a partnering agreement. The member agencies include women's health organizations, disability service providers, local governments and acute health services. The PCP regularly interacts with the member agencies, through meetings, workshops and formal, bi-directional reporting of activities. PCP governance bodies vary, from steering committees to executive committees, and PCPs can be unincorporated or incorporated alliances. In many regions, PCPs form a strategic link between local government, social service providers and the wider community.

As part of the above-mentioned transdisciplinary research project, 22 semi-structured interviews, combined with rich picture exercises (Checkland \& Scholes 1990), were conducted with staff members from 13 PCPs. Each interview lasted between 60 and 90 minutes. The interviews, which focused on understanding both climate change impacts on PCP sector as well as assessing the its capacity to adapt to climate change, highlighted that the remit of their activities and their ability to reach out to wider parts of the community differs significantly from one PCP to another. All PCPs are bound by strategic planning framework issued by the DHHS, which, at the time or the research, provided four broad strategic directions (partnerships; integrated health promotion; chronic disease management; and service coordination) against which each PCP was to develop its own strategic plan, customized to the local socio-economic and institutional context.

For the sector, the strategic planning framework constitutes a powerful attractor regime, which can be considered existential in nature - overarching PCP strategy is driven by the state government and PCPs depend to a large degree on government funding for its implementation. This, combined 
with the already broad scope and resource constraints of PCPs, provides a strong, singular attractor that leaves little feasible room to explore alternative agendas.

Against this backdrop, it is not surprising that the majority of PCPs had not considered climate change impacts and adaptation in their work. The majority of PCP respondents, however, saw the need to consider climate change in their work, especially in relation to the impacts of heatwaves (in particular in urban areas) and prolonged drought (in rural farming areas) on people already socially and economically vulnerable. A common response was that the scope of PCP work is narrowly defined by DHHS and therefore any changes to current strategy would first require significant lobbying, targeting state government bureaucrats and politicians. Some PCPs were involved in informal lobbying that took the form of regularly meeting with DHHS bureaucrats overseeing the funding of PCPs, in particular during the annual reporting cycle. Some of these conversations involved discussing emerging topics of concern, including climate change risk to member agencies and their clients. Others, on the other hand, pointed to resource constraints placing significant limitations on their ability to influence the policy agenda, while also accepting that PCPs were primarily government-funded agencies that were largely driven in a top-down fashion. They pointed out that there was little room to move - in other words, the attractor provided a stable and solid institutional regime.

Nevertheless, the interviews revealed some significant 'outliers' in the sector. For example, Southern Grampians and Glenelg Primary Care Partnership (SGGPCP), located in Hamilton in Victoria's rural south-west, engaged in local collaborative partnerships with community-based environment and sustainability organizations and with universities and research institutes in Australia and overseas, to develop SGGPCP's capacity on climate change issues and attract thirdparty funding that allowed them to implement a project on household energy efficiency and climate change mitigation. In turn, this project developed the SGGPCP's capacity to interpret the relevance of global climate change within the remit of their own organizational goals. Through participating in 
networking events, the organization became known for its work, and other PCPs and social services organizations began looking to it as a resource for ideas and knowledge, creating a tipping set situation for SGGPCP's role in facilitating institutional transformation across the PCP sector. Employing a project-based approach, SGGPCP pushed the boundaries of the PCP strategic planning framework, while continuing to deliver on its core goals, which were dictated by the funding department. In 2008, SGGPCP used its agenda-setting capacity to include climate change mitigation and adaptation in its 2009-2012 Strategic Plan, which constituted a bottom-up institutionalization of climate change in the SGGPCP agenda and provided an institutional tipping point, where the existing attractor regime became replaced, at the organizational level, with an alternative one that had expanded SGGPCP's work to include climate change considerations. The commitment to adaptation, articulated in the strategic plan, demonstrated certainty and continuity to member agencies and ensured that climate change adaptation was not simply a once-off project. In the words of a staff member:

"I think the beauty of our PCP that helps a bit with that is that we're going, that we're keeping [climate change adaptation] as a priority. So even though that project might finish, that we have said that we will provide some capacity to figure out where it fits next..."

Another PCP concerned about the potential impacts of climate change on the sector chose a similar approach to arrive at an organizational level tipping point. Since 2008, the executive officer of South East Healthy Communities Partnership Incorporated (SEHCP $\left.{ }^{2}\right)$, a PCP located in an socioeconomically underprivileged area in the southeastern suburbs of Melbourne, worked closely with the its member agencies, to explore climate change risks specific to its location and socio-economic context, by working with academic and local experts to enter a dialogue on climate change adaptation with practitioners in its partner agencies. As part of these activities, storyboards were developed that linked climate change impacts and adaptation to the core priorities of SEHCP, such as

\footnotetext{
${ }^{2}$ Since the research was carried out, SECHP changed its name to enliven Victoria.
} 
chronic disease management. Through these tipping set activities, the SEHCP earned a reputation for spearheading the development of a practical approach towards integrating climate change adaptation in the work of PCPs and community service organizations as a whole. SEHCP also entertained close and regular contact with government officials at DHHS, to actively promote the relevance of climate change issues by connecting climate change issues with the strategic priorities that the department provided to all PCPs. SEHCP thus created an alternative attractor, where climate change adaptation was increasingly considered relevant to the work of PCPs by the department and across the PCP sector as a whole. As a staff member put it:

“...four years down the track [PCPs working on climate change adaptation] is suddenly starting to feel like a bit of a sector; it didn't feel like we had a sector there before. We were all sort of, apart from a few individuals spotted around, but it is starting to feel now like it is a space and it is a, almost like a new discipline, isn't it, in some respects?

Having developed its own capacity as well as a firm reputation as a leader in this area, SEHCP used the opportunity of needing to develop a new strategic plan by developing a separate strategic objective on climate change adaptation. This was a clear deviation from departmental doctrine, yet it was tolerated by DHHS. It can be argued that the formal institutionalization of climate change adaptation in the PCP's strategic plan marked a tipping point for the whole sector, i.e. a situation where an emerging strategic issue had surpassed the threshold of becoming accepted practice in parts of the sector. The PCP actively contributed to the tipping process by promoting its work through presentations at academic and professional conferences, media work and continuous engagement on the topic in the local area and in regional networks. While, as of early 2016, the PCP strategic planning framework issued by the state government has not changed and still doesn't prescribe climate change adaptation planning, it seems plausible that this may happen in the near future, as the impacts of climate change on community and health services and their clients become increasingly apparent in southeastern Australia. 


\section{Discussion}

In the above case studies, the concept of institutional tipping points was employed to trace and understand how institutional change and transformation occurs at various scales. The distinct categories of attractor regimes, tipping sets, and tipping points were used as conceptual devices, to diagnose the different stages required for an emergent issue to becoming institutionalized as a formal policy agenda. The tipping points framework allows interpreting the process of adopting climate change adaptation as an agenda for policy and action from a sociological institutionalism perspective, where formal and informal institutions, rather than structures and agents, are considered critical in transformation at an organizational level and beyond.

As the Greater Bendigo case showed, the process of organizational change always requires two interlinked conditions to be met: the dominant attractor regime weakens while an alternative attractor emerges. This, naturally, creates a potential tipping point, whose threshold may vary depending on the strength and stability of normative systems in place. The tipping point threshold is higher, where there are deep value-based differences between the dominant and an alternative attractor. In the Bendigo example, the ridge between the dominant (skepticism towards climate change and the need for action) and the alternative attractor (an imperative for climate change adaptation) was indeed significant, but it gradually lowered as state and federal government policy provided an impetus (albeit limited in scope) for considering climate change impacts in local government.

The PCP case study highlighted two things: first, it illustrated the critical and cumulative role that emerging informal institutions play in the process of transformation at the organizational level. The two PCPs both began their journey of organizational change by forming partnerships that allowed for social learning and experimentation, while also gradually developing capacity and ownership for climate change adaptation among staff of member agencies. The informal institutions that proved important during this formative process of building up towards a tipping points also includes 
communicative elements, such as informal chats within the organization and networking with local experts and academics willing to share their experiences, during public events.

When it comes to the process of transforming loose and often ad-hoc activities into formal institutional structures, the two cases showed that 'managing up' within the organization and advocacy to higher levels of authority were two key strategies that preceded the formalization of adaptation within the own organizational context. Here, individual leadership and conviction was a driving factor that warrants further in-depth research.

While the two examples were mainly illustrative in nature and do not provide a comprehensive characterization of all relevant factors that contributed to the institutional system tipping from one attractor regime to another, they do highlight the important role of formal institutions in the tipping process. In both case examples, successfully including adaptation in strategic planning documents marks the single most important characteristic of a tipping point. In the case of local government, this can be largely attributed to the fact that public service organizations are hierarchical in nature and implementation-driven from the top to the bottom, with senior management responsible for implementing strategies and plans, despite these often involving significant bottom-up consultation with, or participation from, the local electorate. In the case of the PCPs, however, the strategic plan not only governed the organization's service delivery, it also proved instrumental for lobbying state government on climate change issues, by highlighting how (and not only that) adaptation was connected to the core mission of PCPs. Here, the strategic plan signified an organizational tipping point, while at the same time helping create a tipping set in relation to the whole PCP sector. Here, the strategic plan signified an organizational tipping point, while at the same time helping create a tipping set in relation to the whole PCP sector. It is yet to be seen if the successful engagement on adaptation of the two PCPs mentioned, combined with other initiatives across the sector, will continue to deepen an alternative attractor, thus enabling a lasting transformation of the sector, where an institutional tipping point is crossed by the majority of PCPs, which would then routinely 
consider the implications of climate change in their strategic planning and day-to-day operational management.

\section{Conclusion}

This paper highlighted the potential for transposing the concept of environmental tipping points in the realm of human social systems, by exploring the concept's key features and opportunities for application. The case study examples, while narrowly focused on the public sector, showed that tipping points can serve as a useful analytical framework for examining processes of institutional change and transformation at different scales.

This paper hopes to open up the discussion about institutional tipping points and much more work is necessary to grasp this concept and how it can be applied to social systems in its full epistemic and methodological depth. There are a large number of unresolved questions that will need to be tackled for productively using the notion of tipping points as a social science framework. Of these, five stand out that will most definitely require further in-depth work.

First of all, any translation of concepts from the natural to the social sciences warrants in-depth critical examination, with regard to its ontological and epistemological stance, as well as its promise of a new contribution to knowledge on social systems. This paper has been mainly concerned with providing just one interpretation of the tipping points idea for the social realm, adopting a somewhat uncritical view to illustrate the concept's potential for social research and provide a basis for more in-depth discussion. It is that such an attempt inevitably results in a framing with strong positivist undertone. A critical question here is whether or not the tipping points concept can in fact provide an interpretive framework to elicit new knowledge on the proliferation (or the absence thereof) of climate change adaptation across sectors, professional groups and other types of social systems. Also, does the notion of institutional tipping points simply provide a positivist and 
seemingly objective lens that facilitates a simplification and misinterpretation of social processes that are, essentially, impossible to grasp in their complexity?

Secondly, further work is required to theorize the questions of sequence, pathways and institutional lock in. A key issue here is to develop theoretical models that capture the uncertainty and messiness of social systems and that take account of power dynamics inherent in any social system. Such research might ask, for example, precisely which factors are critical for enabling that 'outlier' informal institutions add up to a tipping set within a defined sub-group or sub-system? How can existing theories of power and decision-making be used to inform our understanding of institutional attractors and emerging tipping points? Recent work on adaptation decision science and adaptation pathways is promising in this regard. More fundamentally, however, we will need to ask whether it is theoretically sound to connect the idea of social transformation with that of tipping points: which social systems, if any at all, transform through tipping - and is it impossible for gradual, incremental institutional change to lead to transformation?

Thirdly, vast gaps remain in developing an adequate conceptual apparatus that can truly act as a coherent analytical framework. This paper started out from Lenton's important work by appropriating key terms from his work and that of other natural scientists concerned with research into environmental tipping points, but this only scratches the surface of what is required to achieve analytical precision. For example, further conceptual work is required to develop a nomenclature appropriate to the social science - that can accurately describe the various categories that signify the emergence of formal and informal institutions and their combined effects. A risk here is to jump prematurely to a diagnostic typology of sorts, while the actual processes that lead a system to tip in favor of new policy agendas, such as climate change adaptation, remain under-theorized and poorly understood.

Fourthly, the tipping point concept highlights important methodological challenges that also came to the surface in the case studies used in this paper. Here, the full suite of challenges of empirical social 
research applies, some of which institutional researchers have grappled with for long. Retrospective semi-structured interviews and other empirical social research methods may be able to detect tipping points in the past, but a much more interesting and useful goal would be to develop methodologies that allow researchers to decipher the early signs of institutional emergence, pointing to the potential for institutional transformation, whether virtuous or destructive. A main challenge here would be to define the system boundaries and develop nuanced methods to examine clearly defined system elements and their potential for transformation.

Lastly, it seems obvious that translating the tipping point concept into the social realm is likely not going to be productive if social systems are examined in isolation from its ecological counterparts. In particular with regard to climate change, and not least due to the concept's origins in environmental sciences, it would be wise to begin any consideration of institutional tipping points from the basis of bounded socio-ecological systems and the current institutions that govern them - something that the brief case studies presented in this paper failed to do. 


\section{References}

Adger, NW, NW Arnell and EL Tompkins (2005). Successful adaptation to climate change across scales. Global Environmental Change Part A, 15(2), 77-86.

Alley, RB. et al. (2003). Abrupt climate change. Science (New York, N.Y.), 299(5615), 2005-10.

Arnell, NW et al. (2014). The impacts of climate change across the globe: A multi-sectoral assessment. Climatic Change, 134(3), 457-474.

Bardwell, LV (1991). Problem-framing: a perspective on environmental problem-solving. Environmental Management, 15(5), 603-612.

Berkhout, F (2012). Adaptation to climate change by organizations. Wiley Interdisciplinary Reviews: Climate Change, 3(1), 91-106.

Berkhout, F, J Hertin and DM Gann (2006). Learning to adapt: organisational adaptation to climate change impacts. Climatic Change, 78(1), 135-156.

Checkland, P and J Scholes (1990). Soft Systems Methodology in Action, Chichester: John Wiley \& Sons.

City of Greater Bendigo (2009). Council Plan 2009-13 [updated 2011], Bendigo: City of Greater Bendigo.

Delaney, L (2009). Primary Care Partnerships: More than just one relationship. Australian Journal of Primary Health, 15, 212-2117.

Department of Health and Human Services (2015). Primary Care Partnerships. Available at: https://www2.health.vic.gov.au/primary-and-community-health/primary-care/primary-carepartnerships. 
Fünfgeld, H and D McEvoy (2011). Framing climate change adaptation in policy and practice, Melbourne: Victorian Centre for Climate Change Adaptation Research. Available at: http://www.vcccar.org.au/files/vcccar/Framing_project_workingpaper1_190411.pdf.

Garschagen, M (2011). Resilience and organisational institutionalism from a cross-cultural perspective: an exploration based on urban climate change adaptation in Vietnam. Natural Hazards, 67(1), 25-46.

Gifford, R (2011). The dragons of inaction: pychological barriers that limit climate change mitigation and adaptation. The American Psychologist, 66(4), 290-302.

Gifford, R, C Kormos and A McIntyre (2011). Behavioral dimensions of climate change: drivers, responses, barriers, and interventions. Wiley Interdisciplinary Reviews: Climate Change, 2(6), 801-827.

Gladwell, M (2000). The Tipping Point: How Little Things Can Make a Big Difference, Boston: Little, Brown.

Grodzins, M (1957). Metropolitan segregation. Scientific American, 197(4), 33-41.

Hall, PA and RCR Taylor (1996). Political Science and the Three New Institutionalisms. Political Studies, 44(5), 936-957.

IPCC (2014). Climate Change 2014: Impacts, Adaptation, and Vulnerability. Part A: Global and Sectoral Aspects. Contribution of Working Group II to the Fifth Assessment Report of the Intergovernmental Panel on Climate Change, Cambridge, United Kingdom and New York, NY, USA: Cambridge University Press.

Kirkby, M (1995). Modelling the links between vegetation and landforms. Geomorphology, 13(1-4), 319-335. 
Lawrence, J et al. (2013). Adapting to changing climate risk by local government in New Zealand: institutional practice barriers and enablers. Local Environment, 20(3), 1-23.

Leck, $\mathrm{H}$ and D Roberts (2015). What lies beneath: understanding the invisible aspects of municipal climate change governance. Current Opinion in Environmental Sustainability, 13, 61-67.

Lenton, TM (2013). Environmental Tipping Points. Annual Review of Environment and Resources, 38(1), 1-29.

Lenton, TM et al. (2008). Tipping elements in the Earth's climate system. Proceedings of the National Academy of Sciences of the United States of America, 105(6), 1786-93.

Levermann, A et al. (2011). Potential climatic transitions with profound impact on Europe. Climatic Change, 110(3-4), 845-878.

Linnenluecke, MK, A Griffiths and MI Winn (2013). Firm and industry adaptation to climate change: a review of climate adaptation studies in the business and management field. Wiley Interdisciplinary Reviews: Climate Change, 4(5), 397-416.

Measham, TG et al. (2011). Adapting to climate change through local municipal planning: barriers and challenges. Mitigation and Adaptation Strategies for Global Change, 16(8), 1-21.

Meyer, JW \& B Rowan (1977). Institutionalized organizations: formal structure as myth and ceremony. American Journal of Sociology, 83(2), 340-63.

Munck af Rosenschöld, J, JG Rozema, and LA Frye-Levine (2014). Institutional inertia and climate change: a review of the new institutionalist literature. Wiley Interdisciplinary Reviews: Climate Change, 5(5), 639-648.

North, DC (1991). Institutions. Journal of Economic Perspectives, 5(1), 97-112.

O’Neill, S and S Nicholson-Cole (2009). "Fear Won't Do It": Promoting Positive Engagement With 
Climate Change Through Visual and Iconic Representations. Science Communication, 30(3), 355-379.

Park, SE et al. (2012). Informing adaptation responses to climate change through theories of transformation. Global Environmental Change, 22(1), 115-126.

Pelling, M (2011). Adaptation to Climate Change: From Resilience to Transformation, Milton Park / New York: Routledge.

Pelling, M et al. (2008). Shadow spaces for social learning: a relational understanding of adaptive capacity to climate change within organisations. Environment and Planning A, 40(4), 867-884.

Phillips, JD (2006). Evolutionary geomorphology: thresholds and nonlinearity in landform response to environmental change. Hydrology and Earth System Sciences, 10(5), 731-742.

Powell, W and P DiMaggio (1991). The New Institutionalism in Organizational Analysis, Chicago,IL: University of Chicago Press.

Scheffer, M et al. (2001). Catastrophic shifts in ecosystems. Nature, 413(6856), 591-6.

Scheffer, M (2010). Complex systems: Foreseeing tipping points. Nature, 467(7314), 411-412.

Thargard, P and S Findlay (2010). Changing Minds About Climate Change: Belief Revision, Coherence, and Emotion. In EJ Olsson and S. Enqvist, (eds). Belief Revision meets Philosophy of Science. Dordrecht: Springer Netherlands, 329-345.

Victorian Government (2013). Primary Care Partnership Program Logic 2013-17, Melbourne. Available at: http://docs.health.vic.gov.au/docs/doc/5E35B44E161AF5C8CA257ACF00762128/\$FILE/PCP Program Logic consultation draft May 2013.pdf.

Walker, BJ, WN Adger and D Russel (2014). Institutional barriers to climate change adaptation in 
decentralised governance structures: Transport planning in England. Urban Studies, 52(12), $2250-2266$.

Wiest, SL, L Raymond and RA Clawson (2015). Framing, partisan predispositions, and public opinion on climate change. Global Environmental Change, 31, 187-198. 